\title{
Peritoneal changes due to laparoscopic surgery
}

\author{
Tarik Sammour • Arman Kahokehr • \\ Andrew G. Hill
}

Published online: 13 October 2011

(C) Springer Science+Business Media, LLC 2011

We commend the authors for the publication of their very well-written review on the peritoneal effects of laparoscopy [1]. This is a topic of particular interest given the ever-increasing number of surgical procedures being performed laparoscopically [2].

We have two specific comments to make: The first is that much of the laboratory animal research included in the review is based on extremely exaggerated models of laparoscopy. We have recently shown, for example, that almost all published rat studies investigating oxidative stress associated with laparoscopy have used gas flow rates only loosely adapted from the clinical setting (in some instances up to 10 times the equivalent human flow rate) without corrections for animal size or physiology [3]. Insufflation pressures have also tended to be significantly overestimated. It has recently been estimated that the optimal insufflation pressure that should be used in a rat model to simulate human laparoscopy approximates $5 \mathrm{mmHg}$, which is significantly lower than that used in the majority of the studies $(10-15 \mathrm{mmHg}$ ) [4]. These inaccuracies in the scaling of insufflation parameters limit the applicability of these rat models to the clinical setting.

The second comment pertains to the differences in core temperature when using cold versus warmed insufflation gas. Several clinical studies have investigated this effect, but standardisation of external warming devices has been poor and the results have thus been inconclusive [5]. In a

T. Sammour $(\bowtie) \cdot$ A. Kahokehr · A. G. Hill

Department of Surgery, South Auckland Clinical School,

Auckland, New Zealand

e-mail: sammour@xtra.co.nz

T. Sammour · A. Kahokehr · A. G. Hill

Department of Surgery, Faculty of Medical and Health Sciences,

University of Auckland, Auckland, New Zealand recent double-blinded trial in laparoscopic colectomy, where patients were randomised to cold dry gas or warm humidified gas (the use of an external warming device was standardised between groups), differences in intraoperative core temperature were not apparent [6]. In addition, there were no differences in the peritoneal or plasma cytokine response, or in any of the other postoperative recovery parameters measured.

\section{References}

1. Brokelman WJ, Lensvelt M, Borel Rinkes IH, Klinkenbijl JH, Reijnen MM (2011) Peritoneal changes due to laparoscopic surgery. Surg Endosc 25:1-9

2. Sammour T, Mittal A, Loveday BP, Kahokehr A, Phillips AR, Windsor JA, Hill AG (2009) Systematic review of oxidative stress associated with pneumoperitoneum. Br J Surg 96:836-850

3. Sammour T, Mittal A, Delahunt B, Phillips ARJ, Hill AG (2011) Warming and humidification have no effect on oxidative stress during pneumoperitoneum in rats. Minim Invasive Ther Allied Technol. doi:10.3109/13645706.2011.556647

4. Avital S, Itah R, Szomstein S, Rosenthal R, Inbar R, Sckornik Y et al (2009) Correlation of $\mathrm{CO}_{2}$ pneumoperitoneal pressures between rodents and humans. Surg Endosc 23:50-54

5. Sammour T, Kahokehr A, Hill AG (2008) Meta-analysis of the effect of warm humidified insufflation on pain after laparoscopy. Br J Surg 95:950-956

6. Sammour T, Kahokehr A, Hayes J, Hulme-Moir M, Hill AG (2010) Warming and humidification of insufflation carbon dioxide in laparoscopic colonic surgery: a double-blinded randomized controlled trial. Ann Surg 251:1024-1033 